\title{
Presentation of research results
}

5th International Electronic Conference on Water Sciences

$$
\text { 16/11/2020 - 30/11/2020 }
$$

By: Dereje Tadesse Mekonnen

November 16, 2020 Jimma, Ethiopia 


\section{Application of volcanic rocks for the removal of phosphate ions from wastewater}

Dereje Tadesse ${ }^{1,3,{ }^{*}}$, Esayas Alemayehu ${ }^{2}$, Bernd Lennartz ${ }^{3}$

${ }^{1}$ School of Chemical Engineering, Jimma Institute of Technology, Jimma University, P.O.Box 378, Jimma, Ethiopia.

${ }^{2}$ Faculty of Civil and Environmental Engineering, Jimma Institute of Technology, Jimma University, P.O.Box 378, Jimma, Ethiopia.

${ }^{3}$ Faculty of Agricultural and Environmental Science, University of Rostock, Justus Von-Liebig Weg 6, 18059, Rostock, Germany 


\section{Outlines}

- Introduction

- Objectives

- Methods

- Results and discussions

- Conclusions and recommendations

- References

- Acknowledgments 


\section{Introduction}

$>$ Phosphorus(P) removal from water is an important way to control eutrophication

$>\mathrm{P}$ is a very important macro nutrient for aquatic life only if in less amount.

$>$ The main sources of Phosphate to water stream

* Natural source: (Soil erosion, runoff...)

* Anthropogenic source: (industries, municipals, mining ...) .....it is leading

$\square$ Eutrophication(wheninexcessamountofPinwater).Source:https://jamesh oward.us/2017/07/10/eutrophication-reduction-local-limits/

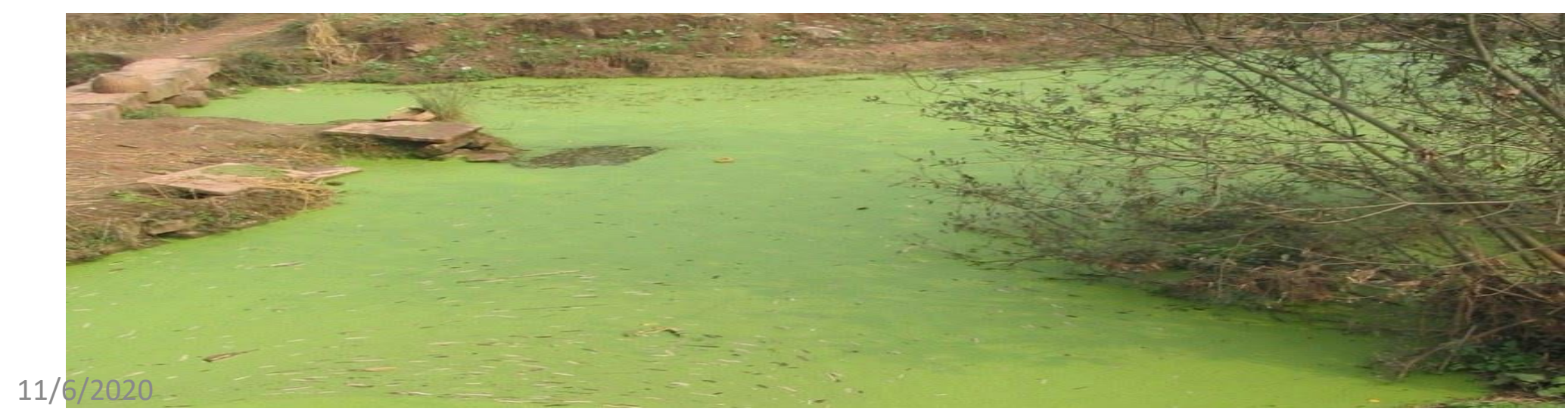




\section{Sources of Phosphate}

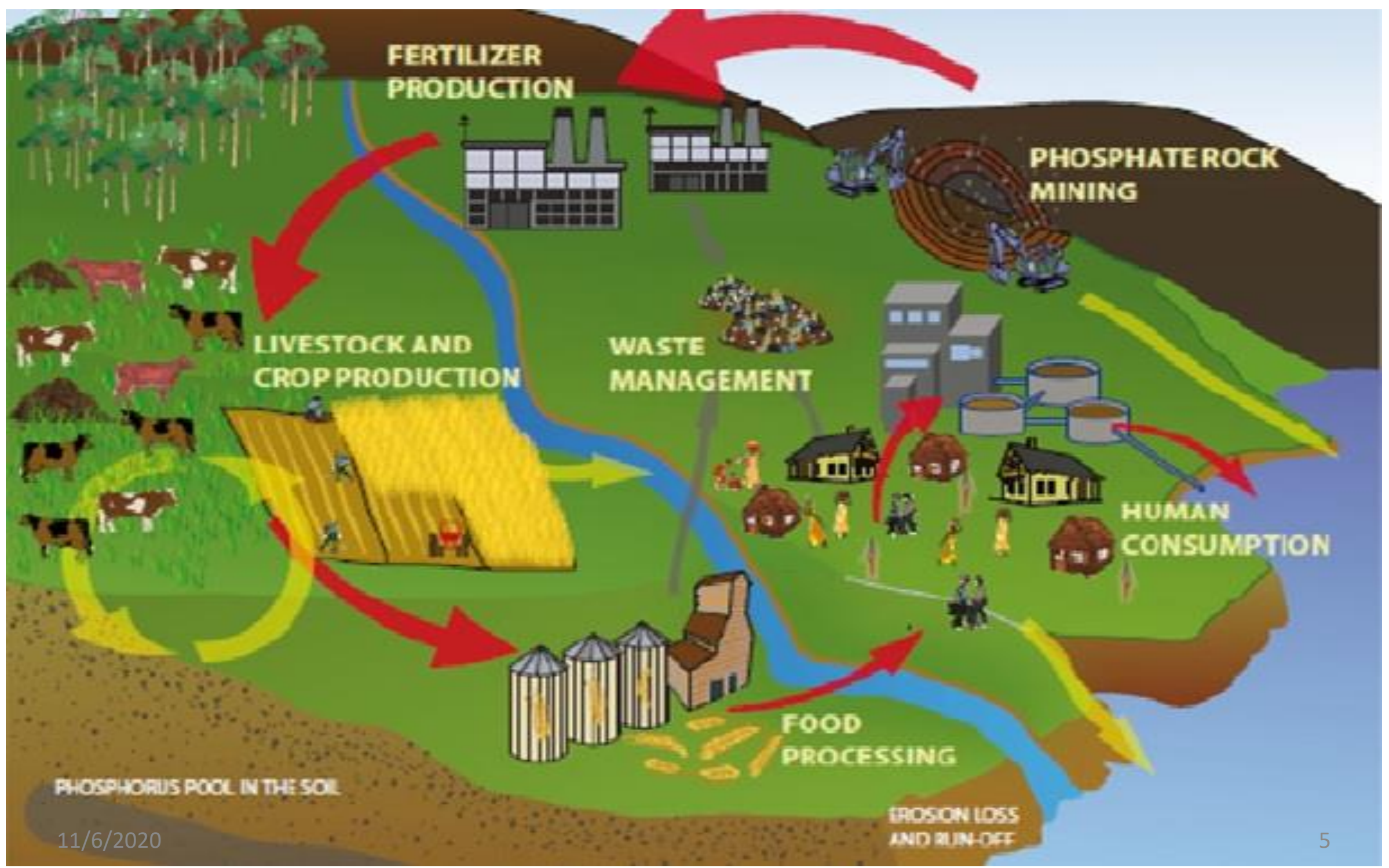




\section{Removal methods}

- Conventional removals (chemical precipitation and biological treatments) are highly applied but due to high cost and complexity of operational procedure, adsorption is becoming preferable removal methods due to its easiness, cost effective and reusability of adsorbents. 


\section{Cont'd...}

$\square$ Various technologies have been developed for phosphate removal where adsorption with different adsorbents is leading this time:

o Coal leftover (Mekonnen et. al 2020)

- Marble waste (Bouamra et al. 2018)

- Nanoscale zerovalent iron(NZVI) (Arshadi et al. 2018)

o Alum sludge (Nawar et al. 2015)

○ Rice husk and fruit juice (Yadav et al. 2014)

o Still slag produced in Europe (Meyer et al. 2012)

- Aleppo pine (Benyoucef and Amrani 2011)

o zirconium(IV) loaded fibrous (Awual et al. 2011), etc.. 


\section{Problem statements}

Why adsorption?

$\checkmark$ Cost and potentials of using of advance technologies

$\checkmark$ simplicity for adsorption technology(easy design and regeneration)

$\checkmark$ Availability of raw materials

$\checkmark$ Cost of raw materials

$\checkmark$ The need of the nation for WWT, ...etc 


\section{Cont'd...}

$>$ Using easy technology i.e. no advance technology required(capacity aspect)

$>$ Reduce hard currency for the advance technology (economical aspect)

$>$ reusing of waste materials (environmental aspect) 


\section{Objectives}

$\checkmark$ To evaluate the removal potential of rock materials(Vpum and Vsco)

$\checkmark$ To evaluate the effects of operational parameters on the removal of Phosphate

$\checkmark$ To evaluate the effects of the coexisting of anions on the removal process. 


\section{Materials and methods}

- Virgin volcanic rocks (Pumice-VPum and ScoriaVSco) from main rift valley of Ethiopia were collected.

- Materials were first washed, dried, ground and treated with metal cations then sonicated to increase adsorption performance using batch experiments.

- Kinetic and equilibrium sorption experiments were conducted in order to examine potential use of the rocks as efficient sorbents 


\section{Cont'd...}

- Reagents: The following reagents were used:

$0.1 \mathrm{M} \mathrm{HCl}, 50 \% \mathrm{H} 2 \mathrm{SO} 4,0.1 \mathrm{M} \mathrm{NaOH}$, ( $\mathrm{NH} 4) 6 \mathrm{Mo} 7 \mathrm{O} 24.4 \mathrm{H} 2 \mathrm{O}$, potassium antimony tartrate ((SbO) K (C4H4) 6). 1/2H2O), ascorbic acid (C6H8O6) and others for the determination of phosphate by photometer. Reagents

- All chemicals and reagents used in this experiment were of analytical grade reagents (AGR) from Merck Germany. 


\section{Cont'd...}

- Working solution preparation: $1000 \mathrm{mg} / \mathrm{L}$ stock solution of $\mathrm{KH} 2 \mathrm{PO} 4$ was diluted to $10 \mathrm{mg} / \mathrm{L}$ except for doze effect $(0.5 \mathrm{mg} / \mathrm{L}-$ $25 \mathrm{mg} / \mathrm{L})$ 


\section{Cont'd...}

- Experimental setups:- 40g/L adsorbent used except for doze effect for batch experiment in $100 \mathrm{ml}$ Erlenmeyer flask with $10 \mathrm{mg} / \mathrm{L}$ Phosphate solution then shaking for $24 \mathrm{hr}$ prior to filtration the suspension solution for photometer detection.

$$
\begin{aligned}
A(\%) & =\frac{(C o-C t)}{C o} X 100 \\
q_{t} & =\frac{(C o-C t) V}{M}
\end{aligned}
$$




\section{Results and discussions}

- The EDX-SEM image indicate the mineralogy chemical composition and surface morphology of the adsorbents

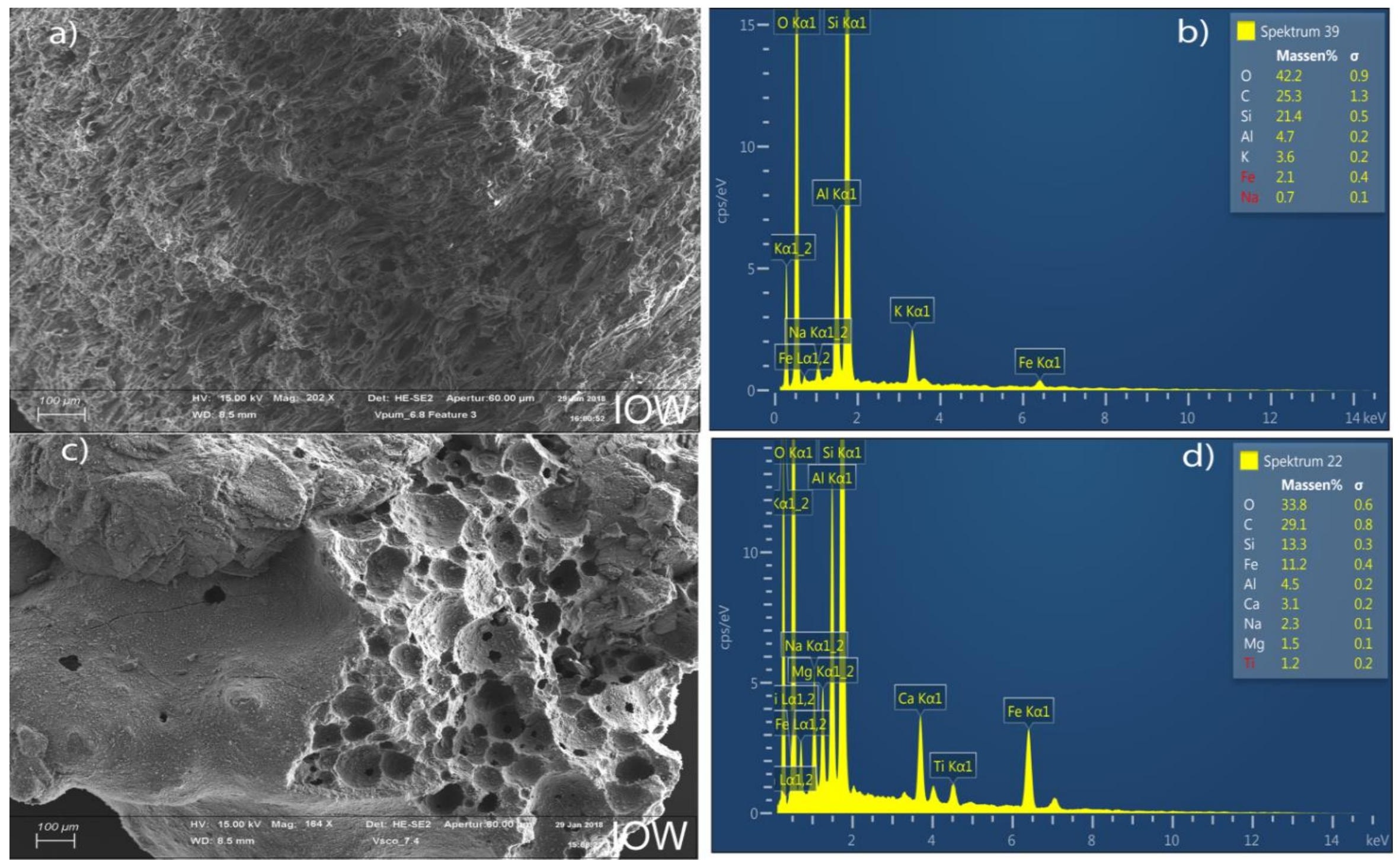




\section{Cont'd...}
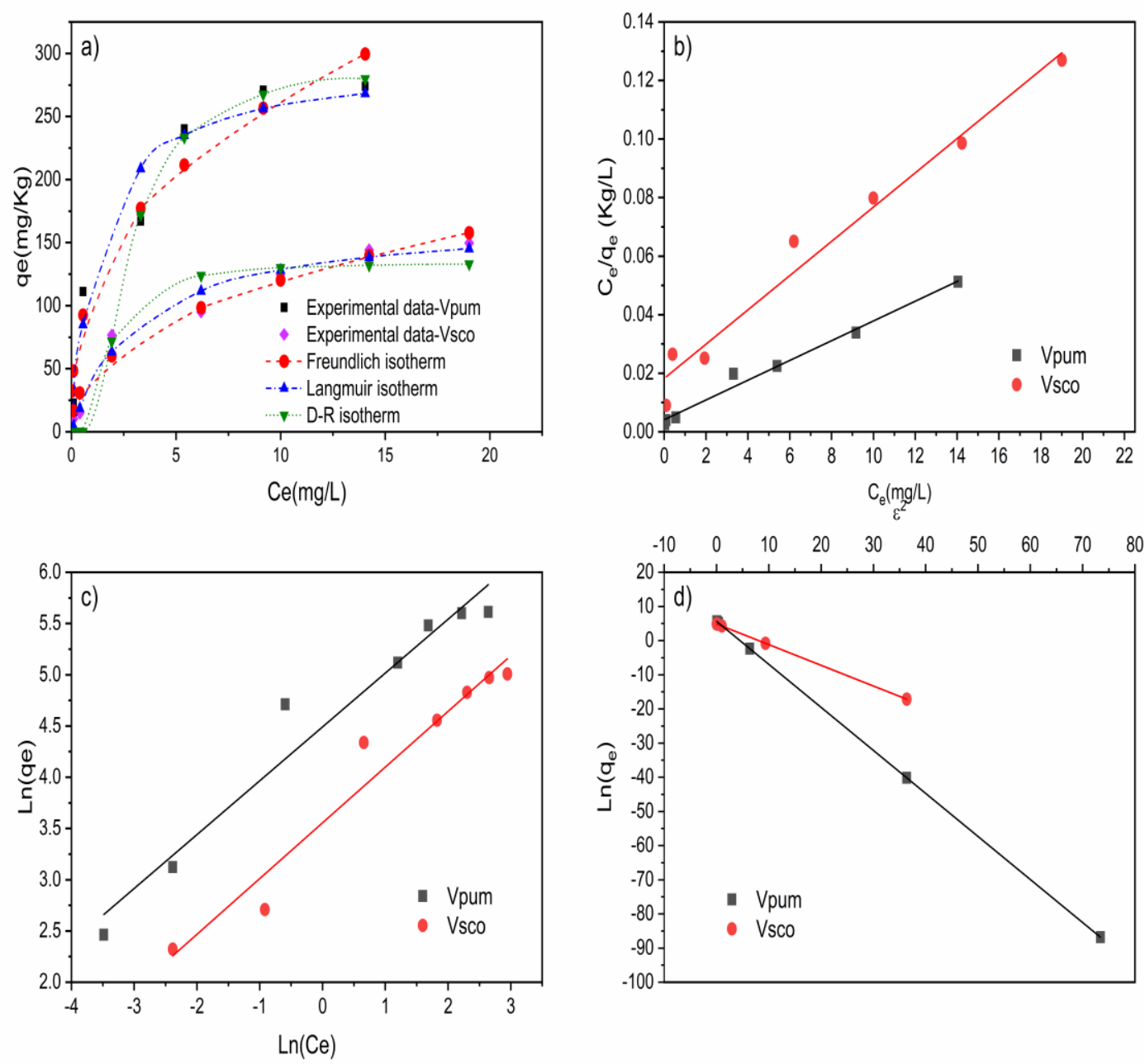

- Concentration effect show raise of removal capacity with increasing initial conc.

- The equilibrium linear plots shows the fit of experimental data with the theoretical one 


\section{Cont'd...}

\begin{tabular}{|c|c|c|c|}
\hline \multirow[b]{2}{*}{ Isotherms } & \multirow[b]{2}{*}{ Parameters } & \multicolumn{2}{|c|}{ Adsorbent } \\
\hline & & Pumice & Scoria \\
\hline \multirow[t]{4}{*}{ Langmuir isotherm } & $\mathrm{KL}(\mathrm{L}$ mg-1) & 0.74 & 0.31 \\
\hline & $q m(m g ~ K g-1)$ & 294.28 & 169.95 \\
\hline & $\mathbf{R}^{2}$ & 0.73 & 0.81 \\
\hline & $\mathbf{R L}$ & $0.05-0.7$ & $0.11-0.87$ \\
\hline \multirow[t]{3}{*}{ Freundlich isotherm } & $\left.((\mathrm{mg} / \mathrm{kg}))_{-1}^{\mathrm{KF}} \mathrm{mg} / \mathrm{L}\right) 1 / \mathrm{n}$ & 114.80 & 45.58 \\
\hline & n & 2.76 & 2.37 \\
\hline & $\mathbf{R}^{2}$ & 0.89 & 0.92 \\
\hline \multirow[t]{4}{*}{$\begin{array}{l}\text { Dubinin Radushkevich is } \\
\text { otherm }\end{array}$} & $q m(m g ~ K g-1)$ & 289.81 & 134.32 \\
\hline & $\mathrm{E}(\mathrm{kJ} \mathrm{mol}-1)$ & 3.31 & 5.44 \\
\hline & B & 0.045 & 0.017 \\
\hline & $\mathbf{R}^{2}$ & 0.80 & 0.69 \\
\hline
\end{tabular}




\section{Cont'd...}
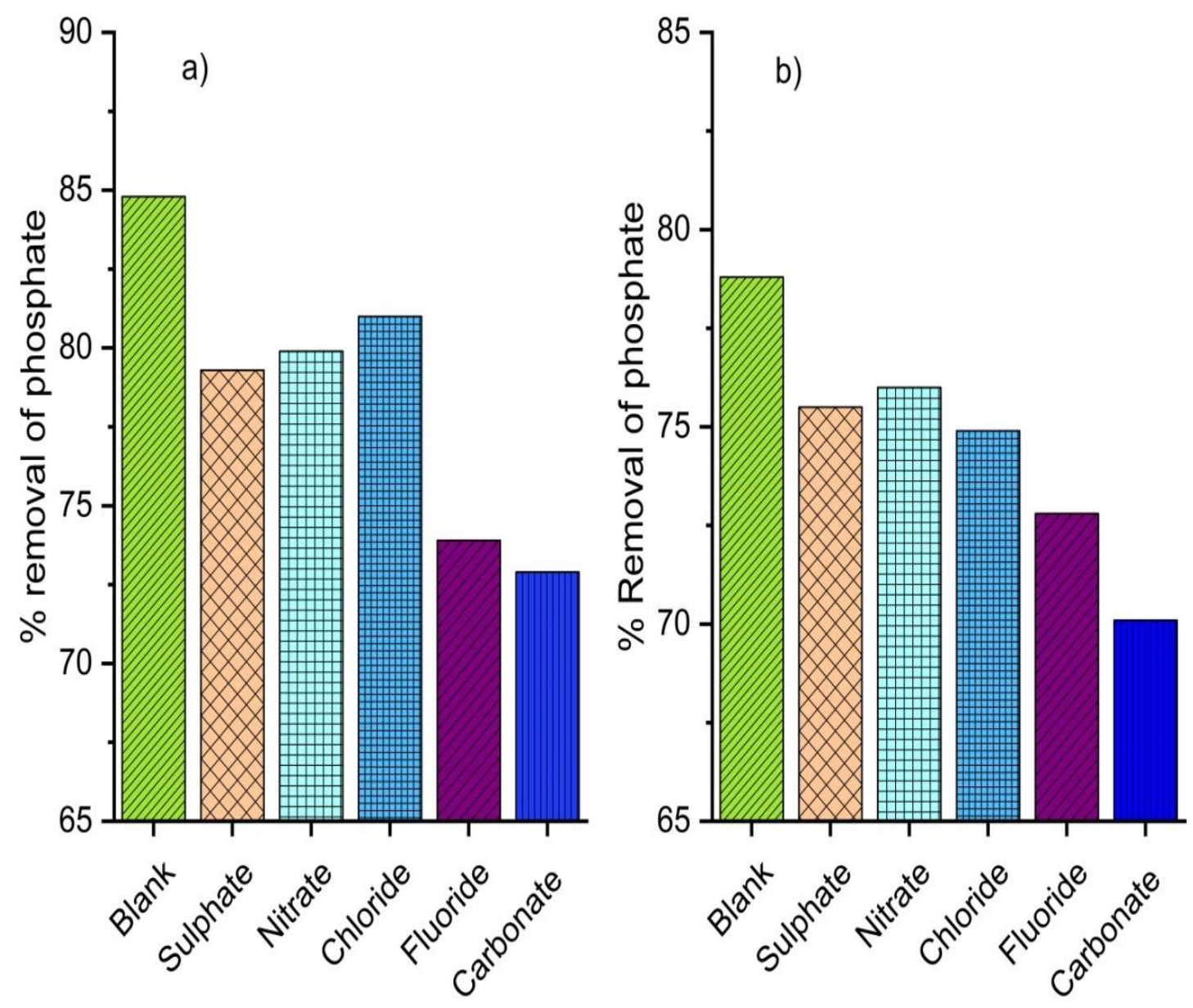

- Coexisting anions affects the adsorption process

- Carbonate makes high effect than others in both Vpum and Vsco

- Nitrate and chloride effect shows simultaneous removal of anions is possible 


\section{Conclusions}

- Study of adsorption kinetics and adsorption isotherm advocate that the adsorption processes mainly occur through chemisorption which indicative of the strong attraction of covalent bond between the adsorbent materials and phosphate ions where the value on mean free energy obtained from Dubinin -Radushkevich isotherm indicated that physisorption also possible in the removal process due to the Van der Waal force of attraction. 


\section{Conclusions cont'd...}

- It was also observed that the removal of phosphate from solution dramatically affected by the presence of competitive anions.

- So that simultaneous removal of pollutants has to be considered during water treatment.

- Overall, virgin volcanic rocks (i.e pumice and scoria) can be used as potential adsorbents for the removal of phosphate from water. 


\section{Future work}

- Additional testing in a flow-through set-up is required to draw definite conclusions.

- Phosphate laden wastewater has to be tested to evaluate the real applicability of the removal and competition of other anions

- Treating the adsorbent(AC) for better adsorption is recommended(but costs of activation has to be considered) 


\section{References}

- Huang, W.; Li, D.; Liu, Z.; Tao, Q.; Zhu, Y.; Yang, J.; Zhang, Y. Kinetics, Isotherm , Thermodynamic, and Adsorption Mechanism Studies of La ( OH ) 3 -Modified Exfoliated Vermiculites as Highly Efficient Phosphate Adsorbents. Chemical Engineering Journal 2014, 236, 191-201, doi: 10.1016/j.cej.2013.09.077

- Lalley, J.; Han, C.; Li, X.; Dionysiou, D. D.; Nadagouda, M. N. Phosphate Adsorption Using Modified Iron Oxide-Based Sorbents in Lake Water: Kinetics, Equilibrium, and Column Tests. Chemical

Engineering Journal 2016, 284, 1386-1396, doi: 10.1016/j.cej.2015.08.114.

- Yadav, D.; Kapur, M.; Kumar, P.; Mondal, M.K. Adsorptive Removal of Phosphate from Aqueous Solution Using Rice Husk and Fruit Juice Residue. Process Saf. Environ. Prot. 2015, 94, 402-409

- Tor, A.; Cengeloglu, Y. Removal of Congo Red from Aqueous Solution by Adsorption onto Acid Activated Red Mud. J. Hazard. Mater. 2006, 138, 409-415

- Asaoka, S.; Yamamoto, T. Characteristics of Phosphate Adsorption onto Granulated Coal Ash in Seawater. Mar. Pollut. Bull. 2010, 60, 1188-1192

- Qiu, B.; Duan, F. Synthesis of Industrial Solid Wastes/Biochar Composites and Their Use for Adsorption of Phosphate: From Surface Properties to Sorption Mechanism. Colloids Surf. A Physicochem. Eng. Asp. 2019, 571, 86-93 


\section{Acknowledgements}

- The authors gratefully thank those who contribute directly or indirectly

- DAAD: for funding for $1^{\text {st }}$ author

- Jimma University

- Rostock University and the communities

- ECWS-5 organizers

$>$ Families and Friends for support 


\section{The End}

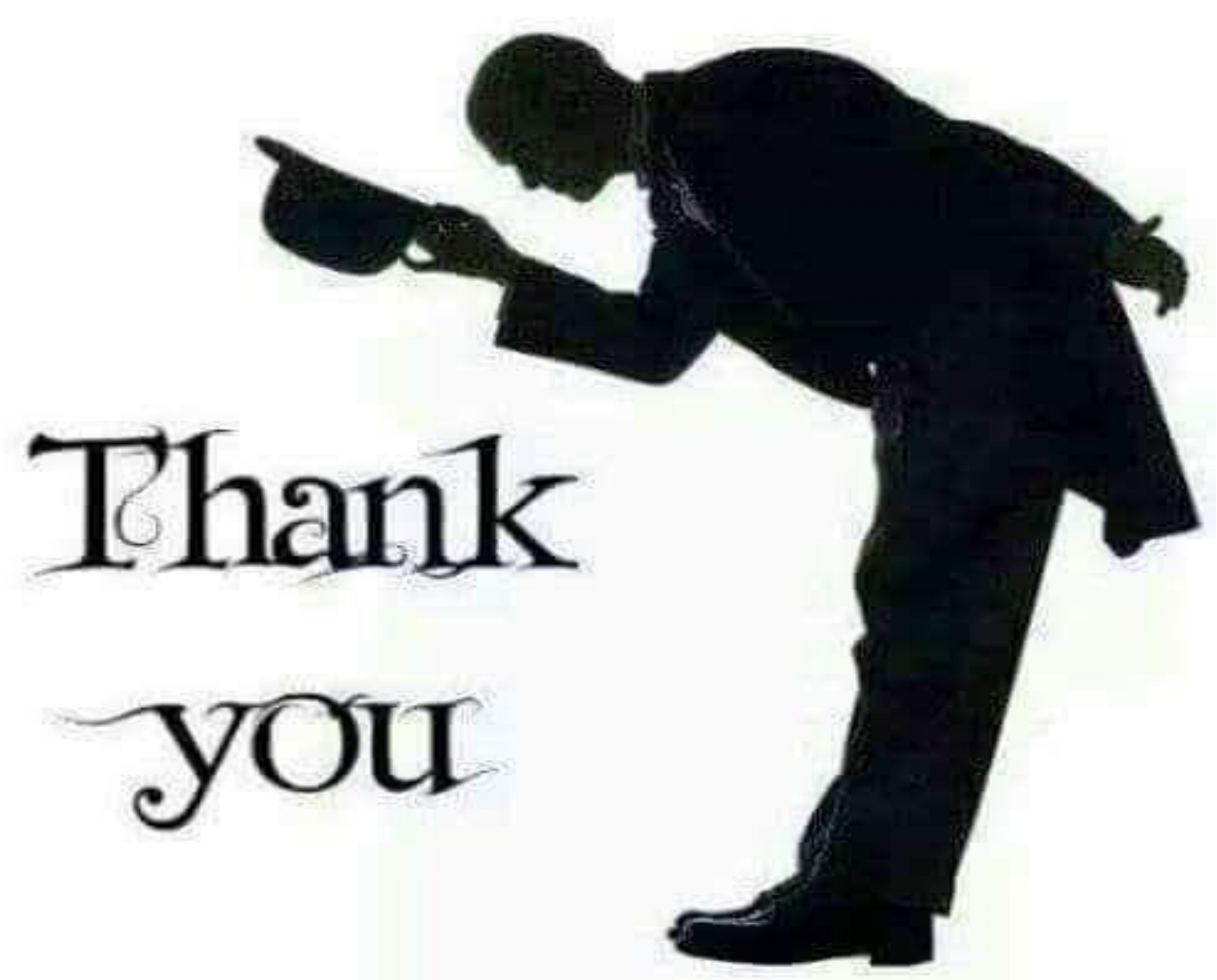

